\title{
ESTRUTURAS VINÁRIAS ANTIGAS DO DOURO (PORTUGAL) COMO RECURSO TURISTICO
}

\author{
José Augusto Maia Marques \\ Instituto Superior da Maia - ISMAI \\ CEDTUR - Centro de Estudos de Desenvolvimento Turístico
}

\begin{abstract}
Resumo: Com base no conhecimento da importância histórica e da riqueza patrimonial e simbólica de la vinha e do vinho, o autor propõe um programa de recuperação, valorização e animação das suas estructuras vinárias antigas como recurso turístico, neste caso no contexto da região vinícola do Douro, Património da Humanidad.
\end{abstract}

Palavras-chave: Estructuras vinárias, recurso turístico, recuperação, valorização, animação.

Abstract: Ancient wine structures of Douro (Portugal) as tourist resource

Being aware of the rich heritage and symbolic importance of vine and wine, the author proposes a program of recovery, reuse and animation of their ancient wine structures as a tourist resource, in this case having as a scenario the Douro Wine Region, a World Heritage Site.

Keywords: wine structures, tourist resources, recovery, reuse, animation

Resumen: Estructuras vinarias antiguas en el Duero (Portugal) como recurso turístico

Basándose en el conocimiento de la importancia histórica y de la riqueza patrimonial y simbólica de los viñedos y del vino, el autor propone un programa de recuperación, revalorización y animación de las viejas estructuras del vino como recurso turístico, en este caso en el contexto de la región vinícola del Duero, Patrimonio de la Humanidad.

Palabras clave: estructuras vinarias, recurso turístico, recuperación, revalorización, animación.

O vinho, já o escrevi antes (Marques, 2009), tem um enorme potencial no que toca ao aproveitamento turístico. Seja directamente no que toca ao seu processo de criação e fabrico, seja no que ele representa como tema e mote de muitas produções da chamada cultura popular desde tempos bem recuados (Marques, 2010).

O que queremos hoje, na sequência aliás desses textos, é propor um programa de aproveitamento da vinha, do vinho e das suas estruturas vinárias como recurso turístico. Escolhemos o Douro pois dificilmente haveria um melhor contexto territorial para exemplificar a nossa proposta. 


\section{O VINHO NA ANTIGUIDADE}

O Vinho tem um papel preponderante no desenvolvimento das civilizações modernas. Nesse aspecto, o "fruto da videira e do trabalho do homem"1 não é ultrapassado por nenhum outro produto agrícola e o "néctar dos deuses" é apreciado há mais de 4000 anos. Mesmo pelos agnósticos.

Paradigmático como exemplo é o comentário que se encontra no Eclesiastes, um dos livros da Bíblia: "Não há nada melhor para o homem do que comer, beber e gozar o bem-estar, fruto do seu trabalho" (Eclesiastes, 2, 24).

Na passagem "Eu sou a videira verdadeira, e o meu pai é o viticultor" (João 15:1-8), Cristo compara-se à videira, afirmando que Deus corta as varas que não dão fruto e limpa as que dão fruto para que produzam ainda mais, numa alusão à igreja, aos discípulos e ao cumprimento dos preceitos.

E não nos esqueçamos que na última ceia Cristo dá a comer o pão e a beber o vinho "Este é o cálice do Meu sangue..." (1 Cor. 11, 23-26), gesto que se repete durante a celebração da Santa Missa.

O Vinho tem, assim, não só uma enorme importância histórica, como um grande peso religioso e uma forte carga simbólica.

Acabou por constituir uma marca profunda na matriz civilizacional europeia, mormente na Europa do sul, produtora por excelência, e para quem o vinho tinha, por isso, uma grande importância que vinha já bem de longe.

De facto, o vinho e a vinha tinham, na Antiguidade, certas características que os tornavam algo de sagrado. A videira perde as suas folhas no inverno para depois ressurgir e dar frutos. Arbusto especular dos ciclos da Natureza, a vinha "morre" e "ressuscita"; proporcionando o vinho que aquece no frio, traz a alegria indispensável, propicia o afugentar os maus espíritos e, devidamente ingerido, pode elevar o homem a uma condição sobre-humana - portanto quase divina - permitindo-lhe ver o mundo de outro modo, ou encontrar um mundo "diferente".

Embora a Arqueologia nos diga que em Çatal Hüyük na Turquia, em Damasco na Síria, em Byblos no Líbano e na Jordânia havia sementes de uvas no Neolítico, de cerca de 8000 a.C., e que as mais antigas sementes de uvas cultivadas (de vitis vinifera) foram descobertas na Geórgia (Rússia) e datam de 7000 - 5000 a.C., as primeiras representações artísticas atestando o processo de vinificação remontam a cerca de 3000 a.C. no Egipto (JOHNSON, 1989, 22). Esta cronologia corresponde também a uma utilização mais generalizada da bebida.

Diz-se, aliás ${ }^{2}$, que os egípcios foram pioneiros não só na enologia propriamente dita, mas também os primeiros a registar quer por escrito ${ }^{3}$, quer graficamente com várias

1 Expressão utilizada na celebração da Missa.

2 Cf. Alexandre Camanho de Assis. Vinhos, Rios, Deuses e Civilizações - I - O Egito. OficinaArtium. Consultável em http://www.officinaartium.org/Vinho_Egito.pdf, acedido em 19/02/2012.

3 Diz-se que a primeira palavra decifrada por Jean-François Champollion, quando em 1822 começou o seu 
pinturas, os métodos de vinificação, armazenamento e transporte do vinho. O mesmo aconteceria com o que hoje chamamos rotulagem: cada vasilha, sobretudo se tinha destino real ou nobre, continha informações sobre a casta da uva ${ }^{4}$, a colheita e a origem ${ }^{5}$.

Cultivado na Antiga Grécia, cerca de 1000 a.C. estendeu-se para as ilhas gregas e para o Mediterrâneo, nomeadamente nos territórios que são hoje Espanha e Itália. Depois, com a fundação de Marselha, o vinho estende-se àquele que é ainda hoje um dos seus territórios mais conceituados - a França.

Os vinhos da Antiga Grécia eram considerados de grande categoria e foram imortalizados por poetas, historiadores e artistas. Até no plano religioso, com destaque para Dionísio, muito venerado, o vinho teve papel fundamental.

Como os egípcios, os gregos consideravam o vinho um "privilégio" das classes mais abastadas, e ele não era consumido pelo cidadão comum.

Os antigos romanos, que receberam o vinho dos gregos provavelmente cerca de 800 a.C., davam grande importância ao desenvolvimento e cultivo da vinha e tiveram um papel significativo na disseminação do vinho. Durante o apogeu do Império Romano, depois de 50 a.C., a produção de vinho espalhou-se pela maior parte da Europa, incluindo França, Espanha, Itália e mesmo algumas partes da Britânia.

Sabe-se que em Roma normalmente o vinho não era consumido puro, mas sim «temperado» com água (Amato, 2004: 127). Os adegueiros, graças a recipientes graduados que doseavam a mistura, cuidavam da preparação que era normalmente de duas partes de vinho para três de água e uma pitada de sal. Não admira por isso que, neste período, o vinho se fosse tornando mais acessível também às massas. Cidades como Pompeia chegaram a construir estabelecimentos em quase todas as ruas para promover a venda $\mathrm{e}$ o consumo de vinho.

Usava-se também o vinho aromatizado com ervas e especiarias (tomilho, erva-doce, mirtilo, sambuco).

Como os romanos gostavam de vinhos doces, ou faziam colheitas tardias ou deixavam o fruto secar um pouco ao sol, produzindo vinhos designados passum, ou ainda misturavam-no com mel, tendo neste caso a designação de mulsum.

As classes mais pobres mesmo assim utilizavam uma beberagem de vinho azedo ou vinagre, misturado com água e temperado com ervas, a que davam o nome de posca.

O culto de Baco gerou muitos seguidores. Se os gregos idolatravam Dionísio, os romanos cultuavam Baco, celebrado em muitos festivais. E o vinho era, assim, e entre muitos outros, um factor de transgressão. Mas também, em vários preparados, foi utilizado com fins medicinais.

Lucius Junius Moderatus, por alcunha Columela, da cidade de Gades (Cádiz), escreveu, cerca de 65 d.C., um verdadeiro «manual» em doze volumes intitulado "De re

trabalho com os hieróglifos da famosa Pedra de Roseta, teria sido "yrp" - vinho. A palavra figura na sua Grammaire Égyptienne.

4 Mareótida, Tanítica, Teniótida, Tebíada, Sebenítica, Manfesiana, Ecbolada, etc.

5 Segundo Assis (op. cit.), entre os quarenta cântaros que acompanharam Tutankamon no túmulo, haveria um em que poderia ler-se: «Ano 9, vinho do sítio de Tutankamon, do rio ocidental». 
Rustica". No capítulo dedicado ao vinho e à vinha, o manual entra em preciosos detalhes como sejam a produção por área plantada, a técnica de plantio em estacas com distância de dois passos entre elas (sensivelmente a mesma técnica usada hoje em vários locais da Europa,), o tipo de terreno, a drenagem, a técnica de colheita, a prensagem, os modos de fermentação, etc.

Os romanos desempenharam um papel tão importante na disseminação da vinicultura no Ocidente que muitos estudiosos actuais — como Johnson (1989) e Philips (2000) — em várias passagens dos seus trabalhos comparam os hábitos de consumo e a paixão romana pelo vinho com a presente no ocidente globalizado do século XXI, embora em nossa opinião, o que está por detrás dessas «paixões», são motivações e perspectivas totalmente diferentes.

Como afirma Gerson Ribeiro (Ribeiro, 2011: 6) "Para os romanos, o vinho era um produto muito especial, presente em quase todos os aspectos da vida cotidiana. $\mathrm{O}$ vinho selava transacções comerciais, alegrava os banquetes dos patrícios, mitigava as agruras existenciais dos plebeus pobres, tornava palatáveis os remédios amargos receitados pelos médicos da época. Junto com o trigo e o azeite de oliveira, o vinho formava o tripé que sustentava a economia agrícola romana. A expansão militar e territorial romana possibilitou a divulgação das técnicas do cultivo da videira e da produção do vinho, bem como o hábito do consumo dessa bebida-alimento por toda a Europa Ocidental. A influência romana causou um efeito profundo na história de todas as regiões viníferas da França, Alemanha, Itália, Portugal e Espanha".

Crê-se que a vinha terá sido introduzida na Península Ibérica (no nosso caso português no vale do Tejo e no vale do Sado) talvez antes de 1000 a.C. pelos Tartéssios.

Os Fenícios terão trazido novas castas e tomaram conta do comércio do vinho dos Tartéssios cerca do século IX/VIII a.C. Os Gregos instalaram-se na Península Ibérica no século VII a.C. desenvolveram a cultura da vinha e trouxeram progressos nos métodos de fazer o vinho. Cerca do século VI a.C. são introduzidas novas castas de uvas na Península Ibérica.

Como refere Brochado de Almeida (Almeida 1996: 18), é com a conquista romana que o Alto Douro se torna capaz de produzir a trilogia fundamental da alimentação romana - trigo, azeite e vinho.

Foi de facto com a chegada dos romanos à Península, que no sector vitivinícola se deu, como em muitos outros, um enorme salto qualitativo.

São os romanos que introduzem a poda em Portugal e são eles também que criam os socalcos.

Uma das razões que levou ao incremento no plantio de vinha foi o facto de o vinho ser um dos modos de pagamento aos soldados das legiões. Assim, para além das que já aqui existiriam e daquelas que os tartéssios, fenícios, cartagineses e gregos tinham por sua vez trazido, os romanos plantaram também muitas vinhas, daqui resultando uma enorme variedade e profusão de castas, e uma produção relevante.

As estruturas vinária romanas (e posteriores) existentes sobretudo no norte e centro de Portugal são exemplo deste fervilhar da viticultura. 


\section{AS ESTRUTURAS VINÁRIAS DURIENSES}

Não é nossa intenção trazer aqui um estudo arqueológico-histórico sobre as estruturas vinárias antigas no Douro. Esse estudo tem vindo a ser feito por vários investigadores, com destaque para a Arqueohoje em Tabuaço (Arqueohoje, 1999), António Sá Coixão em Fozcoa (Coixão, 1996) e, sobretudo, Carlos Brochado de Almeida ${ }^{6}$ que, para além de estudos monográficos, como por exemplo os lagares de Alijó (Almeida, 1992-1993) e Meda e a estrutura da Vila Romana da Fonte do Milho em Canelas, na Régua, tem vindo a produzir importantes reflexões sobre esta problemática (Almeida, C. A. B.; Antunes, J. M. V. \& Faria, P. F. B. 1999).

Também entendemos não ser este o lugar nem a ocasião para dissertarmos longamente sobre a cronologia destes monumentos. Romanos? Medievais? Porque não ambos, e até modernos?

Figura 1

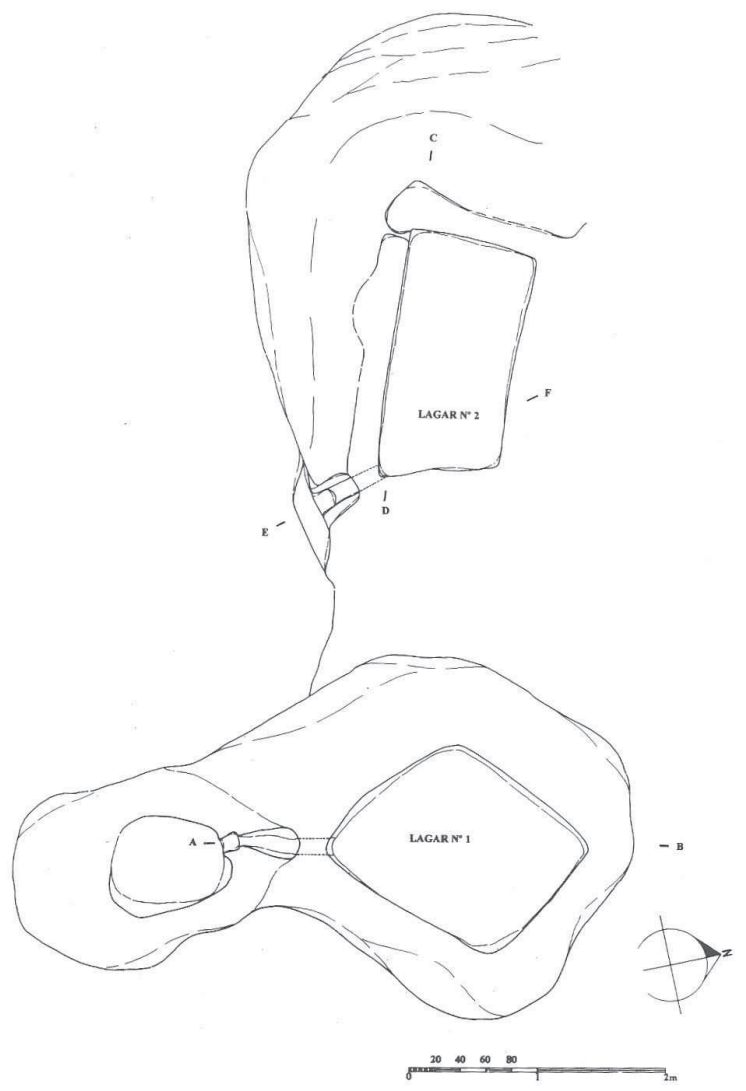

6 São muitos os trabalhos de Brochado de Almeida sobre este tema. Vão elencados na Bibliografia final. 
Figura 2

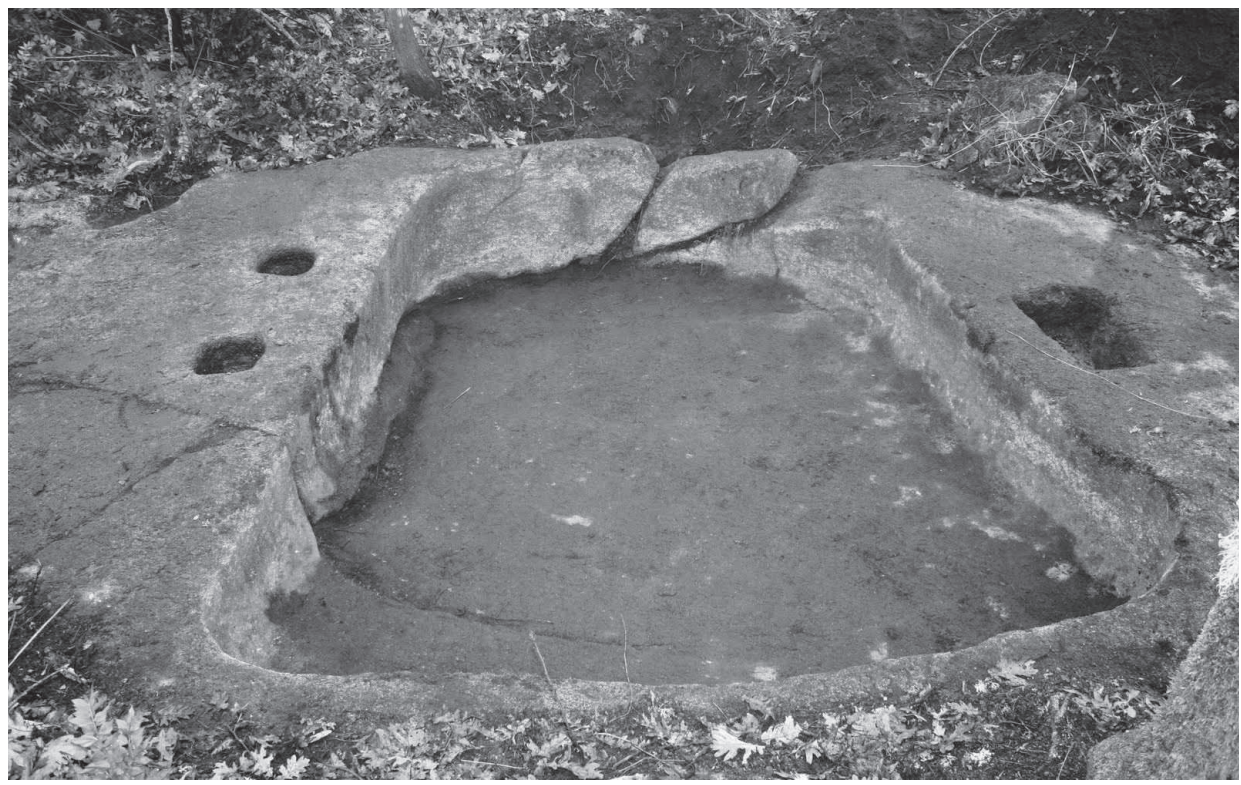

Se não existir contexto arqueológico, difícil se torna precisar datas. Alguns estão em contexto castrejo/romanizado como o do Castro de Lama de Ouriço - Valpaços (Freitas, 2001). No entorno de vários outros têm sido recolhidos vestígios, nomeadamente cerâmicos, que apontam para uma cronologia romana. Por outro lado, o facto de haver ainda pessoas idosas que se lembram na sua juventude de ver alguns em funcionamento, ou de os seus pais lhes terem falado nisso, não nos admira nada, porquanto é perfeitamente possível que em meios rurais de povoamento disperso os pequenos proprietários se servissem deles, ainda que eventualmente de modo diverso do inicial.

Também não é importante, na circunstância, o «velho dilema» vinho ou azeite. De facto, grande parte destas estruturas tem similitudes morfológicas muito grandes, sendo basicamente constituídos por duas cavidades abertas na rocha, rodeadas de um conjunto maior ou menor de orifícios, como vemos no desenho dos lagares de Castelo de Castorigo, Fig. 1 em Pegarinhos, concelho de Alijó, ou na foto do de Lebução, concelho de Valpaços Fig. 2. Mas é preciso não esquecer que com a utilização do modelo do torcularium, como propõe Brochado de Almeida (Almeida, Antunes \& Faria 1999) e no que concorre a maior parte dos que se dedicam a estes estudos, qualquer dos trabalhos podia ser feito. Mais ainda, a diferença cronológica entre prensagem da azeitona (fim do outono, princípio do inverno) e prensagem do vinho (fim do verão, início do outono), possibilitava cabalmente servir aos dois propósitos. 
Figura 3

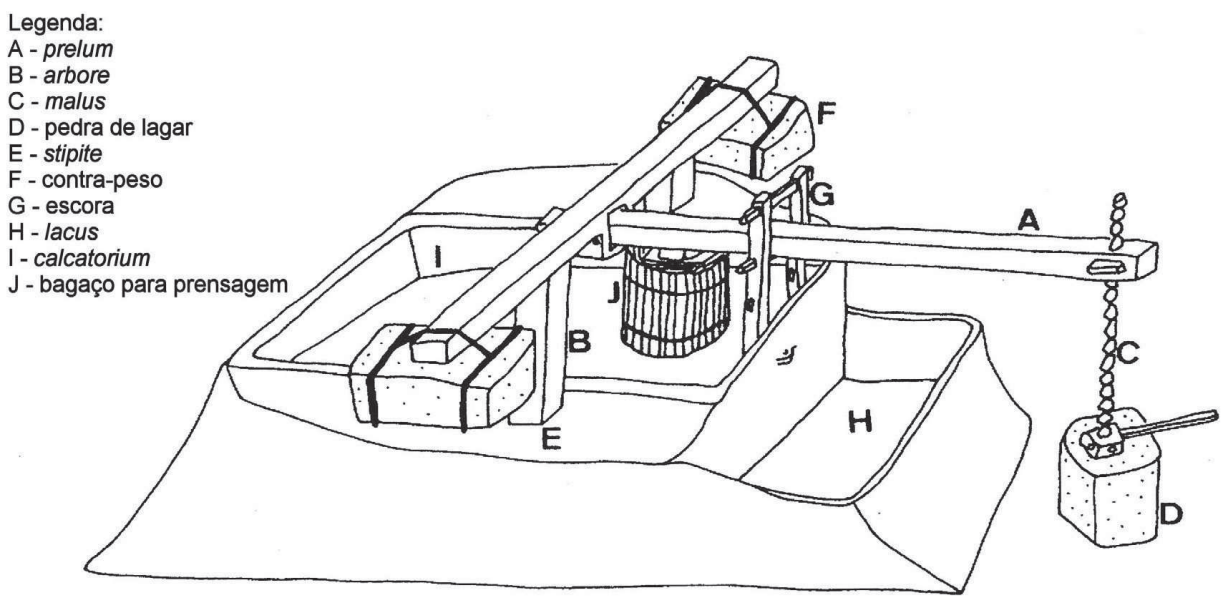

\section{O QUE FAZER COM ELAS?}

Então que queremos trazer-vos aqui?

A possibilidade de utilização destas estruturas vinárias antigas como recurso turístico. Tão simples, e tão complicado como isto.

Que estruturas são essas?

Em primeiro lugar os chamados lagares abertos na rocha.

Normalmente, é uma estrutura simples formada por três elementos principais: um depósito de dimensões variáveis onde eram esmagadas as uvas, uma pia para onde escorria o mosto e um canal de ligação entre ambos. Este sistema repete-se em quase todos os lagares conhecidos, variando apenas em alguns pormenores que não alteram em nada o esquema geral de funcionamento.

Alguns lagares foram simplesmente lavrados em afloramentos graníticos elevados e não possuem pia para recepção do mosto. Possivelmente utilizava-se, como pensa, e bem, Brochado de Almeida, talhas cerâmicas para receber o líquido. E, nesse caso, encontramos um orifício no bordo do único recipiente, para facilitar esse escoamento.

Segundo este autor, os lagares da região do Douro integravam-se no mesmo "modelo tipo" de torcularium (prensa) Fig. 3 constituído por um calcatorium (pia para pisa), um lacus (pio), um par de stipites (buracos de poste), duas arbores (poste de apoio da vara), um prelum (vara de lagar) e um malus (parafuso) munido de um peso, a "pedra do lagar" no vocabulário popular. Uma ceira ou uma estrutura em madeira continham as uvas esmagadas com os pés para serem prensadas (Almeida, Antunes \& Faria 1999).

Dos lagares mais antigos apenas subsistiram os elementos em pedra como o calcatorium onde se esmagavam as uvas com os pés e o lacus que recolhia o mosto. Em alguns casos encontra-se também o peso em pedra que era fixado na extremidade do malus.

Em alguns casos, a existência de outros buracos de poste sugere uma cobertura efémera do lagar, o que também se compreende. 
Estes lagares abertos na rocha, com mais ou menos abundância, encontram-se disseminados pelo território duriense. E cada vez que se avança com prospecção, outros vão sendo reconhecidos.

Como se pode verificar nestas duas fotos do conjunto de lagares de Carlão, Alijó, Fig. 4 e 5 a sua morfologia, o seu entorno, a sua situação geográfica fazem deles potenciais locais de interesse turístico.

Figura 4

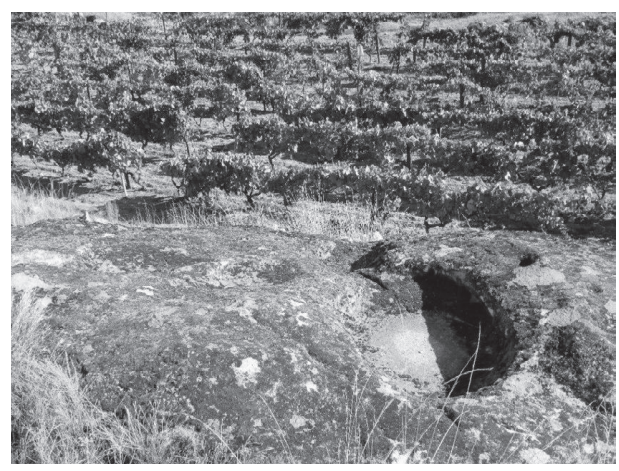

Figura 5

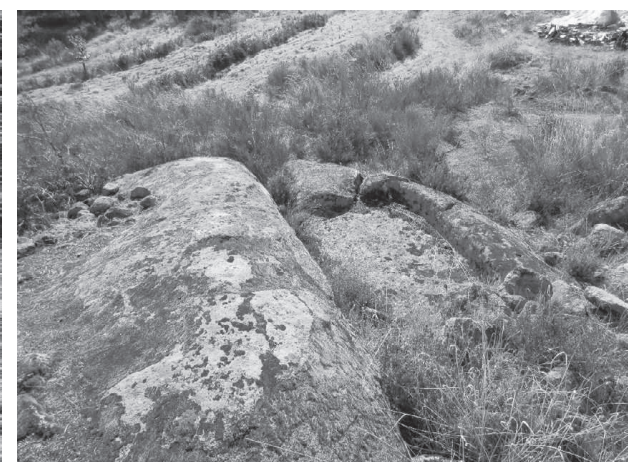

Outra estrutura, de algum modo a «jóia da coroa» deste conjunto, poderia (poderá) ser a Vila Romana da Fonte do Milho, que Russell Cortez nos anos 40 consagrou sob a designação de Castellum da Fonte do Milho.

Trata-se de uma Vila romana fortificada, com vestígios arqueológicos do século I d.C. ao século IV/V d.C. Esta vila romana apresenta um sistema defensivo constituído por duas linhas de muralha erguidas em xisto com o respectivo acesso localizado a SO, característica que, no conjunto, lhe tem conferido a designação geral de "castellum" ou de "villa fortificada". Foi parcialmente estudada por Russell Cortez em meados do século passado (Cortez, 1951)

Vários autores reviram o local e os materiais, com destaque óbvio para Jorge de Alarcão (Alarcão, 1996), e também para recente reflexão de Brochado de Almeida (Almeida, 2006).

De entre os achados merecem uma especial menção os mosaicos com figuras de peixe e os vestígios de uma estrutura vinária. Fig. 6 
Figura 6

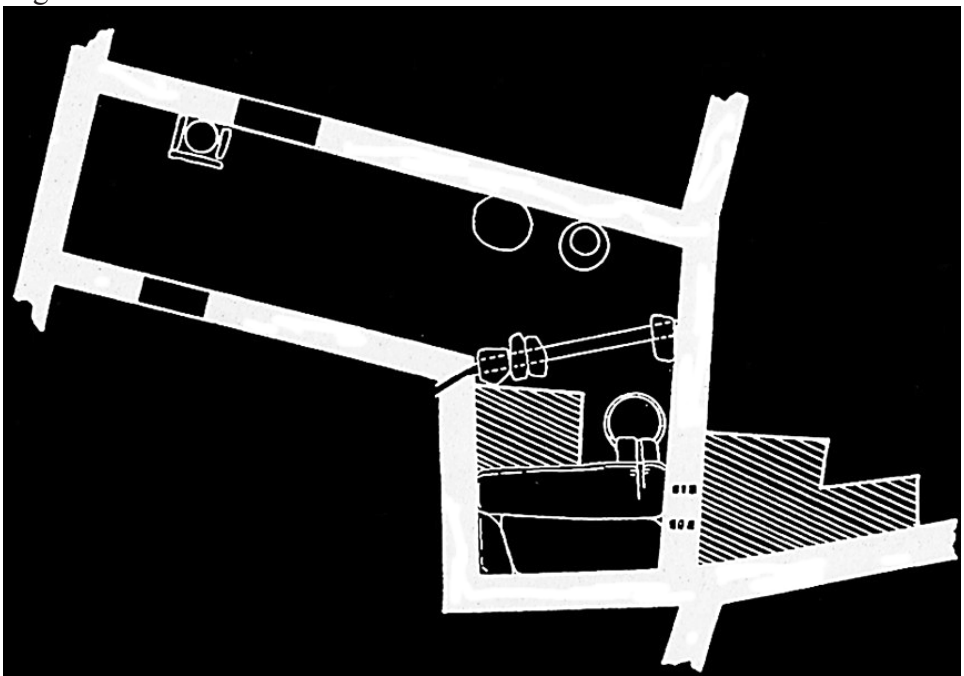

É com estas peças que pretendo sugerir o aproveitamento como recurso turístico.

O que fazer então?

Dividiria as coisas em quatro níveis de actuação, em princípio sequentes, mas que em alguns casos podem ser simultâneos:

NÍVEL I

- Um levantamento exaustivo do território, desde as fontes documentais até à prospecção exaustiva, metro a metro, socalco a socalco, monte a monte. Está mais do que provado, e sei-o por experiência própria, que só assim se detectam as coisas, claro, mas também é só assim que se compreendem. As pessoas viviam (e vivem) num território, e as suas acções e vestígios só assim podem ser compreendidos;

- Esse levantamento exaustivo pressupõe cartografar, fotografar, georreferenciar, recolher notas, entrevistar, em suma, reunir o maior número possível de dados sobre estas estruturas. E que magnífica publicação não dará um trabalho destes;

- Depois é necessário escolher, seleccionar, quais os que farão parte da «rota», ou seja como for que queiram chamar a este «produto» que, no seu final, será turístico. Terá de haver critérios. No meu ponto de vista devem pautar-se pela qualidade do que apresentam ao eventual visitante (os mais completos, os mais simples, em ambos os casos os mais bem conservados), da sua maior ou menor acessibilidade e da facilidade em melhora-la, da maior ou menor integração numa rota (coerência tipológica, coerência formal, coerência territorial), da existência, ou não, de outro património próximo que se articule com este, etc., etc. 


\section{NÍVEL II}

Escolhidos aqueles que vão fazer parte da proposta, é necessário prestar aos monumentos os nossos cuidados:

- Limpar e preparar o local, o que pode inclusive significar intervenções arqueológicas;

- Eventualmente elaborar um pequeno projecto de Arquitectura e/ou paisagismo para um melhor enquadramento (em grande parte dos casos as Câmaras Municipais possuem técnicos que poderão fazê-lo);

- Preparar as acessibilidades, não só o caminho propriamente dito, como toda a sinalização que nos levará ao lugar (é bom não nos esquecermos que a maioria dos visitantes não conhece minimamente o local, logo é preciso dar indicações suficientes para um correcto acesso - atenção às angustiantes rotundas e aos preocupantes cruzamentos sem qualquer referência);

- Dotar o local de sinalização adequada, que mostre claramente ao visitante onde está; essa sinalização deve responder às quatro perguntas sacramentais - O que é isto? O que se fazia aqui? Como funcionava? Que histórias há à volta disto? Um enquadramento histórico, estético e funcional é fundamental; há que ter atenção à linguagem e à ilustração que devem ser pedagógicas, mas não primárias, imbecilizantes, nem acientíficas;

- Construir uma série de materiais informativos - desdobráveis, mapas, postais, brochuras, conteúdos multimédia (uma página na internet, outras nas redes sociais são fundamentais), conteúdos esses que, da página, possam ser descarregados para o telemóvel e utilizados no local como se se tratasse de um áudio-guia de um museu.

\section{NÍVEL III}

Depois de termos o roteiro delimitado, os locais acessíveis e valorizados, as pessoas a circular e a visitar (não se esqueçam de, na página internet colocar um acesso para deixar sugestões, apreciações, etc.), temos de ir mais longe. O passo seguinte passa por:

- Animar, e este animar tem um sentido lato, por exemplo, pegar numa secção de uma banda filarmónica, ou mesmo na banda toda, e executar pequenos concertos nestes locais. Conheço alguns onde o efeito seria certamente surpreendente, a começar pela Fonte do Milho; o mesmo se pode fazer com apresentações de grupos folclóricos, de dança contemporânea, de corais, de contadores de histórias, de concertinas ao desafio, enfim, quase diria do que se quiser e do que se tiver disponível;

- Promover visitas guiadas; para além do público em geral, especialmente famílias, eventualmente mais aos fins-de-semana, há dois planos de público que importa conquistar - um é dos estudantes, nomeadamente do ensino secundário, já tradicionais «clientes» voluntários ou mais ou menos forçados destas coisas; outro, mais recente, mas com maior substrato 
e muito maior apetência é o dos seniores, nomeadamente das universidades seniores, cada vez menos negligenciável pelos programadores;

- Fazer recriações; não devemos ter medo da coisa; devemos é controlá-la com o conhecimento; inúmeras feiras, festas e eventos rotulados de «medievais», a culminar na Viagem Medieval de Santa Maria da Feira são hoje sucessos garantidos; se assegurarmos um grau de cientificidade, de autenticidade, e se aplicarmos esta «receita» às nossas estruturas vinárias, poderemos ter algo semelhante àquilo que fizeram no Lagar Rupestre de Cortegaça, situado na freguesia de Subportela, em Viana do Castelo, no contexto do Encontro Nacional de Enoturismo em 23 e 24 de Setembro de 2011. Fig. 7 Foi um sucesso e já se pensa em dar um carácter periódico ao evento.

E finalmente eis-nos no

Figura 7
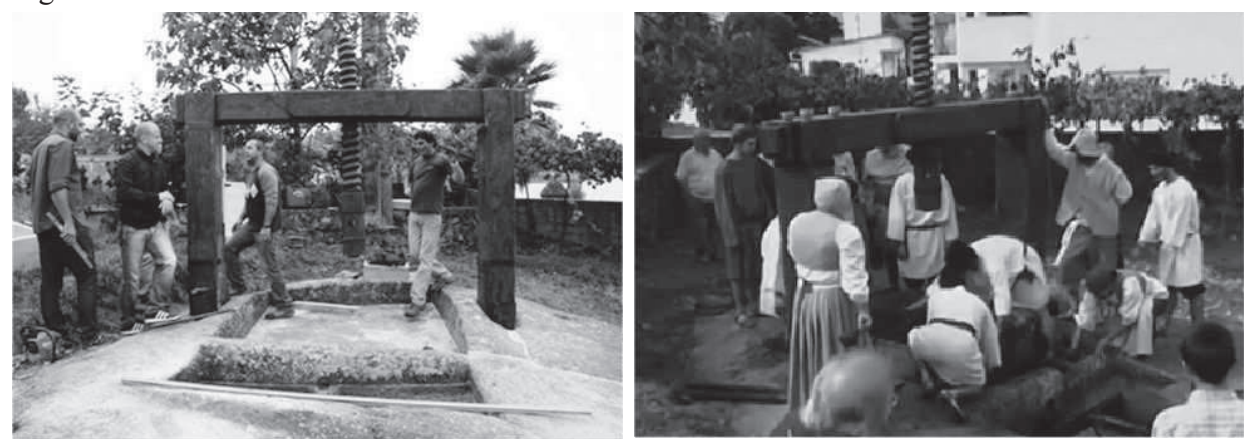

\section{NÍVEL IV}

Chegamos ao cume. Ou quase. Não que seja algo de novo, de bombástico. Bem pelo contrário. Mas é, sem dúvida algo a que não estamos habituados, pelo menos ao nível que vos trago aqui.

Mesmo antes do cume estaria a reconstituição. Partindo do que existia e/ou do que se sabia, reconstituir o monumento, a estrutura, a peça.

Também não é nada de transcendente. No caso em apreço, os modelos genéricos são bem conhecidos, como atesta este modelo Fig. 8 que acompanha um dos trabalhos de Jean-Pierre Adam (Adam, 1989). 
Figura 8

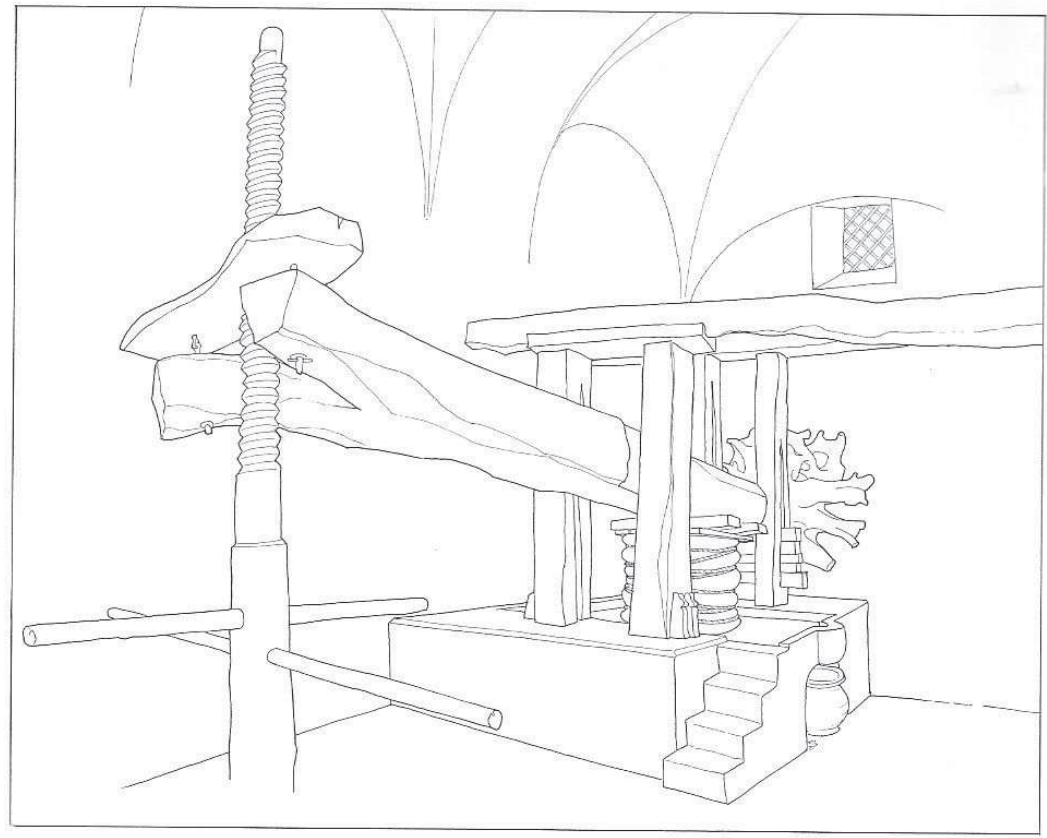

Mas mesmo entre nós há trabalho feito, e bom. É ver os modelos apresentados por João Antunes e Pedro Faria (Antunes e Faria, 2002) e por Susana Cosme (Cosme, 2001), para além do já citado de Brochado de Almeida e outros (Almeida, Antunes \& Faria 1999)

Trata-se portanto de aplicar esses modelos à recuperação. Tal como aconteceu em Oeiras com um lagar que, sendo de azeite, para o efeito em apreço serve perfeitamente como exemplo de fazer bem. Ou em Vila Flor, com um lagar também de azeite, que domina a entrada poente da vila Fig 9.

Há casos específicos de escavações que nos revelam realidades formalmente diferentes mas funcionalmente idênticas, como este exemplo galo-romano de Saint-Romain en Gal (França) Fig 10.

Depois, num patamar já extravasando para a questão comercial, com que quero terminar, está este exemplo de Saint Genet, de um torcularium, isto é, de um lagar de uma Vila Romana das imediações Fig 11, que foi reconstituído, que entra num complexo de brindes e souvenirs e que, sobretudo, deu o nome a uma série de vinhos de sucesso de um produtor - Cuvée du Pressoir Romain.

E, no cume dos cumes, o caso/exemplo de Mas de Tourelle. A cereja no topo do bolo desta proposta. Aqui, com forte acompanhamento científico (arqueólogos, historiadores, palinólogos, enólogos, agrónomos, biólogos, museólogos, antracólogos, etc., etc.), foi possível realizar uma obra que é sem dúvida modelar.

Com base em dados arqueológicos e em texto clássicos, reconstitui-se toda uma estrutura vinária que também ela deu nome a vinhos e é passível de ser visitada Fig 12. 
Figura 9

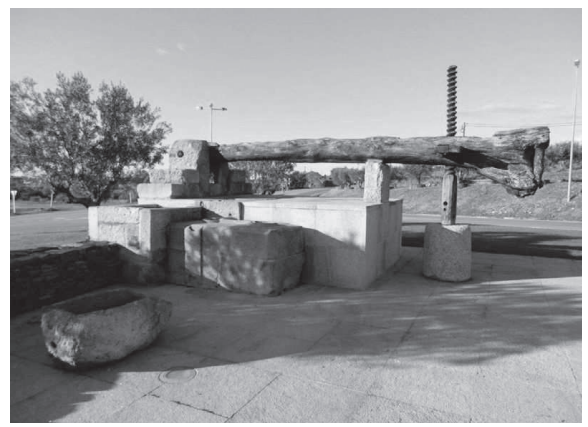

Figura 11

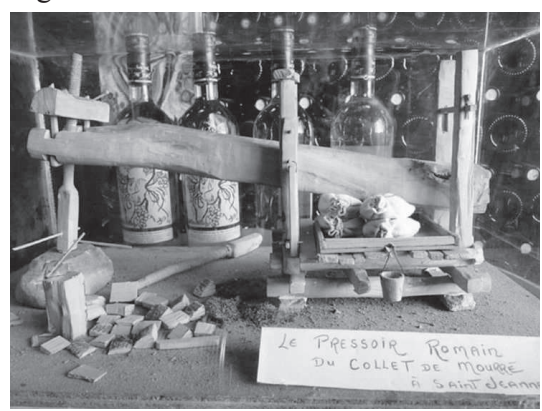

Figura 10

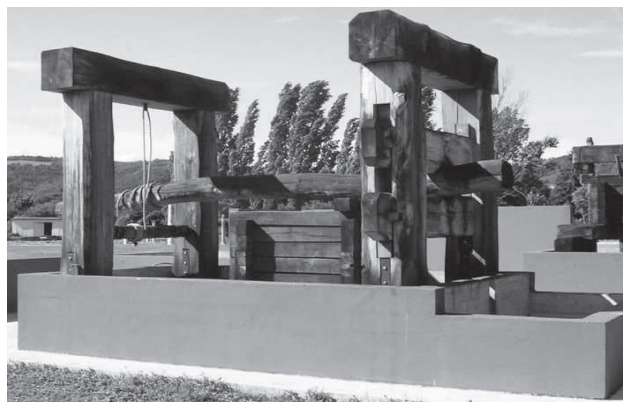

Figura 12

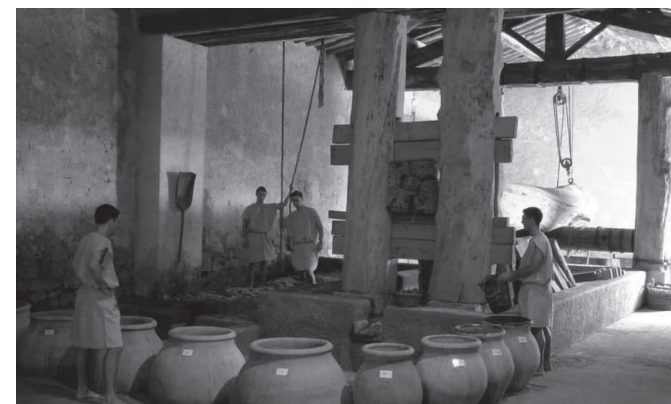

Mas foi-se muito mais longe. Aproveitou-se a arqueologia para o marketing, como mostra o cuidado (até histórico-arqueológico) posto nas embalagens; conservaram-se e musealizaram-se vestígios de estruturas e de materiais, hoje visitáveis; reconstitui-se o torcularium propriamente dito e a cella vinaria em que estava integrado, com todas as suas estruturas; produziram-se elementos de informação/publicidade, que, evidenciando um carácter de divulgação histórica, é quase uma forma de publicidade subliminar ao produto final - o vinho.

E foi-se mais longe ainda, creio que tão longe quanto se pode ir nas actuais circunstâncias.

Reconstituíram-se cientificamente, através de análises a restos, a trabalhos de biologia e até de análises de A D N vegetal de alguns vestígios, as qualidades e características do vinho romano (mais leve, mais aromático, etc.) isto, claro, dentro das modernas exigências.

Reconstituiu-se a estrutura vinária, não apenas para visitante ver, mas para servir efectivamente para fazer milhares de litros que encherão milhares de garrafas de vinho.

Recriou-se a vinha romana, com castas que foram utilizadas, e que subsistiram, algumas na gália mas muitas na península itálica, e utilizando a mesma filosofia de construir as vinhas e as mesmas matérias-primas para esteios, ramadas, etc..

As vindimas são feitas «à romana» por pessoas que disputam avidamente a possibilidade de, cada ano, participarem nestas tarefas, pagando a peso de ouro esse privilégio - curiosa esta nossa civilização - pagar para fazer o papel que nas vilas romanas cabia normalmente aos escravos. 
Elaborou-se uma exposição permanente sobre a ruralidade galo-romana que provavelmente a esta hora já estará transformada numa verdadeira (e grande) unidade museológica.

Aplicar esta «receita» entre nós, mormente no Douro vinhateiro será uma utopia? Creio que não. É mobilizar Universidades, Autarquias, Associações culturais, privados, nomeadamente ligados às questões vinícolas, e bem poderemos ter um Fonte do Milho tinto reserva 2017 ou 2018, feito no lagar que se reconstituiu com base naquela cela vinária.

Creio que em parte o caminho para o desenvolvimento turístico duriense passará inevitavelmente por aqui.

\section{REFERÊNCIAS BIBLIOGRÁFICAS}

Adam, J.-P. (1989): La construction romaine - matériaux et techniques. Paris: Picard.

Alarcão, J. (1996): Roman Portugal. Warminster: Aris \& Philips.

Almeida, C. A. B. (1992-1993) : "O Passado romano de Carlão - Alijó”. Portugália, XIII-XIV, p. 229-261.

Almeida, C. A. B. (1996): "O cultivo da vinha durante a antiguidade clássica na região demarcada do Douro. Ponto da situação”, Douro - Estudos e Documentos, vol. I (2), pp. 18-30.

Almeida, C. A. B. (2004): "O cultivo da vinha na antiguidade clássica", em Carlos A. Brochado de Almeida (coord.) História do Douro e do Vinho do Porto, vol. I, Porto, Edições Afrontamento, pp. 348-404.

Almeida, C. A. B. (2006): "A Villa do Castellum da Fonte do Milho", Douro - Estudos e Documentos, $\mathrm{n}^{\mathrm{o}} 21$, pp. 209-228.

Almeida, C. A. B.; Pinto, P. J. C. \& Almeida, P. M. D. B. (1996): “Os lagares cavados na rocha do castelo de Castorigo - Pegarinhos (Alijó). Douro - Estudos e Documentos, Vol. 2 (4), p. 15-24.

Almeida, C. A. B.; Antunes, J. M. V. \& Faria, P. F. B. (1999): "Lagares cavados na rocha: uma reminiscência do passado na tradição da técnica vinícola no vale do Douro. Revista Portuguesa de Arqueologia, 2 (2), Lisboa: Instituto Português de Arqueologia, p. 97-103.

Amato, F. M. (2004): La Cucina di Roma antica. Roma: Newton \& Crompton.

Antunes, J. V.; Faria, P. B. (2002): "Lagares do Alto Douro Sul. Tipologias e Tecnologias". Douro - Estudos e Documentos, Vol. 7 (14), p. 65-77.

Arqueohoje (1999): Tabuaço - um passado presente. Tabuaço: Câmara Municipal de Tabuaço.

Assis, A. C. A. (s/d): Vinhos, Rios, Deuses e Civilizações - I - O Egito. OficinaArtium. Consultável em http://www.officinaartium.org/Vinho_Egito.pdf acedido em 19/02/2012. 
Coixão, A. N. S. (1996): Carta Arqueológica do Concelho de Vila Nova de Fozcôa. Vila Nova de Fozcôa: Câmara Municipal de Fozcôa.

Cortez, F. R. (1951): As Escavações Arqueológicas do Castellum da Fonte do Milho. Porto: Instituto do Vinho do Porto.

Cosme, S. R. (2001): "O lagar romano de de Aldeia Nova / Olival dos Telhões (Almendra - Vila Nova de Fozcôa)" Douro - Estudos e Documentos, Vol. 6 (12), p. 55-62.

Freitas, A. M.: (2001): Concelho de Valpaços. Carta Arqueológica. Valpaços: Câmara Municipal.

Johnson, H. (1989): The Story of Wine. London: Mitchell-Beazley.

Marques, J. A. M. (2009): "Saberes e Patrimónios do Vinho. Para a sustentabilidade do enoturismo e do turismo em espaço rural". Actas das I Jornadas Internacionais sobre Enoturismo e Turismo em espaço rural. Maia: ISMAI / APVIN/GEHVID.

Marques, J. A. M. (2010): “«O Bom Vinho Escusa Pregão» - O vinho na cultura popular do séc. XVII". Actas do I Congresso Internacional Vinho Verde, História, Economia, Sociedade e Património. Porto: APVIN/GEHVID, Confraria do Vinho do Porto.

Philips, R. (2000): A Short History of Wine. London: Harper Collins Publishers.

Ribeiro, G. L. (2010): O Vinho no mundo romano. Rio de Janeiro: Universidade Cândido Mendes.

\section{CRÉDITOS DAS ILUSTRAÇÕES:}

1 e 3 - Carlos Brochado de Almeida

2 - Graça Gomes em (http://lebucaodevalpacos.blogspot.pt/2011/12/lagares-cavados-narocha-reminiscencia.html consultado em 16/6/2012)

4,5 e 9 - autor

6 - Jorge de Alarcão (ALARCÃO, 1996)

7 - Miguel Costa

8 - Jean-Pierre Adam (ADAM, 1989)

10 - Forum Legio VIII Augusta

11 - Domaine des Hautes Colinnes

12 - Mas de Tourelles - entreprise viticole 